\title{
Papers
}

\section{Fetal growth and subsequent risk of breast cancer: results from long term follow up of Swedish cohort}

\author{
V A McCormack, I dos Santos Silva, B L De Stavola, R Mohsen, D A Leon, H O Lithell
}

\begin{abstract}
Objective To investigate whether size at birth and rate of fetal growth influence the risk of breast cancer in adulthood.

Design Cohort identified from detailed birth records, with $97 \%$ follow up.

Setting Uppsala Academic Hospital, Sweden. Participants 5358 singleton females born during 1915-29, alive and traced to the 1960 census.

Main outcome measures Incidence of breast cancer before (at age $<50$ years) and after $(\geqslant 50$ years) the menopause.

Results Size at birth was positively associated with rates of breast cancer in premenopausal women. In women who weighed $\geqslant 4000 \mathrm{~g}$ at birth rates of breast cancer were 3.5 times (95\% confidence interval 1.3 to 9.3) those in women of similar gestational age who weighed $<3000 \mathrm{~g}$ at birth. Rates in women in the top fifths of the distributions of birth length and head circumference were 3.4 (1.5 to 7.9) and 4.0 (1.6 to 10.0) times those in the lowest fifths (adjusted for gestational age). The effect of birth weight disappeared after adjustment for birth length or head circumference, whereas the effects of birth length and head circumference remained significant after adjustment for birth weight. For a given size at birth, gestational age was inversely associated with risk ( $\mathrm{P}=0.03$ for linear trend). Adjustment for markers of adult risk factors did not affect these findings. Birth size was not associated with rates of breast cancer in postmenopausal women.
\end{abstract}

Conclusions Size at birth, particularly length and head circumference, is associated with risk of breast cancer in women aged $<50$ years. Fetal growth rate, as measured by birth size adjusted for gestational age, rather than size at birth may be the aetiologically relevant factor in premenopausal breast cancer.

\section{Introduction}

In 1990, Trichopoulos proposed the hypothesis that breast cancer may originate in utero. ${ }^{1}$ Eight casecontrol studies, ${ }^{2-9}$ one nested case-control study, ${ }^{10}$ and one cohort study ${ }^{11}$ have used birth weight as a marker of the in utero environment to investigate this hypothesis. Three studies found positive linear associations with birth weight, ${ }^{9-11}$ while $\mathrm{J}$ shaped associations were found in four others. ${ }^{367}$ The effect of other measures of birth size $\mathrm{s}^{359}$ and gestational age $\mathrm{a}^{51017}$ have been examined more rarely.

We investigated possible associations between fetal growth and risk of breast cancer using data from a large Swedish cohort with long and virtually complete follow up. The cohort benefits from data on several birth characteristics and on markers of adult risk factors based on census data. These data allowed us to examine the independent effect of each measure of birth size on risk of breast cancer before and after the menopause, while controlling for some established risk factors for breast cancer. In addition, the availability of data on gestational age provide a unique opportunity to assess the effect of fetal growth rate, measured by birth size adjusted for gestational age, distinct from size at birth on risk of breast cancer.

\section{Methods}

Data sources

The Uppsala birth cohort comprises all people delivered at the Uppsala Academic Hospital during 1915-29. ${ }^{12}{ }^{13}$ The cohort was followed up initially through parish archives, which record all births, deaths, and changes of residence. Since the introduction of personal identity numbers in the 1950 s records could be linked to the registers of deaths and migration and the Swedish Cancer Registry to provide the relevant data for computing incidence rates for breast cancer and to the 1960 and 1970 censuses for data on adult characteristics.

We analysed incidence of breast cancer in 5358 singleton females in this cohort for whom linkage to the 1960 census records was successful and for whom subsequent breast cancer registration (ICD-7 (international classification of diseases, seventh revision) code 170) could be ascertained through the Swedish Cancer Registry (established in 1958).

Birth characteristics recorded at the time of birth included birth weight (measured to the nearest $10 \mathrm{~g}$ ), birth length (recorded to the nearest $0.5 \mathrm{~cm}$ ), head circumference, gestational age (calculated as the time between the mother's last day of menses and delivery date), birth order (calculated as the mother's total previous live and stillbirths), and multiple births.

The 1960 and 1970 censuses provided information on proxy variables for some established risk factors for breast cancer. Age at first marriage and single marital status (recorded at 1960 census) were taken as correlates

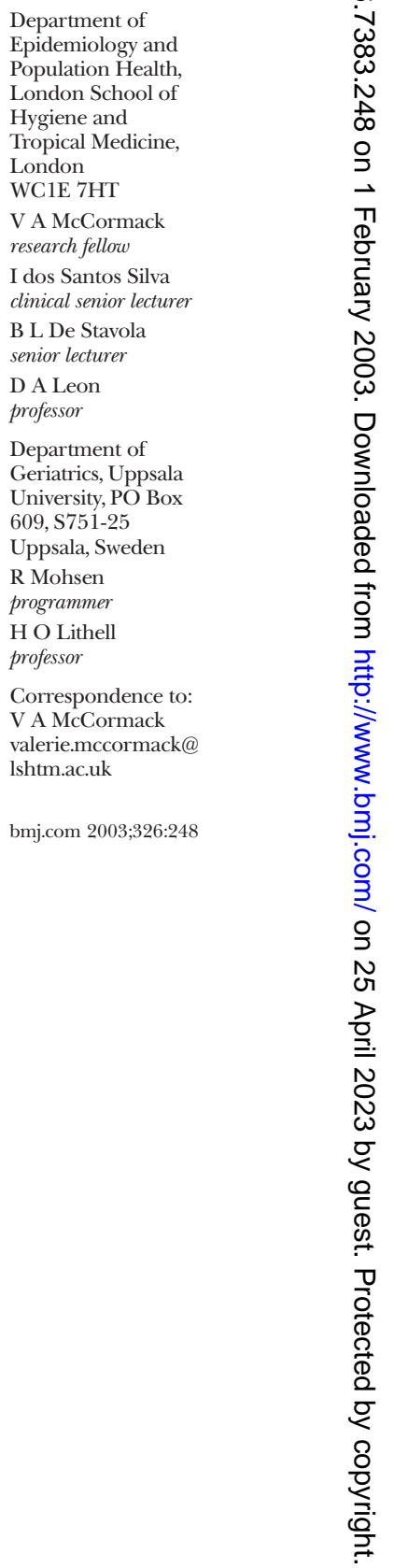


Table 1 Baseline characteristics of eligible study participants by breast cancer status during follow up from 1960-98 and age at diagnosis, Uppsala birth cohort study. Figures are means (SD)

\begin{tabular}{lccc} 
Characteristic & $\begin{array}{c}\text { No cancer } \\
(\mathbf{n}=\mathbf{4 9 9 9 )}\end{array}$ & $\begin{array}{c}\text { Age }<\mathbf{5 0} \text { years at } \\
\text { diagnosis }(\mathbf{n = 6 3 )}\end{array}$ & $\begin{array}{c}\text { Age } \geqslant \mathbf{5 0} \text { years at } \\
\text { diagnosis }(\mathbf{n}=\mathbf{2 9 6})\end{array}$ \\
\hline Birth weight $(\mathrm{g})$ & $3396(497)$ & $3491(528)$ & $3406(500)$ \\
\hline Birth length $(\mathrm{cm})$ & $50.4(2.2)$ & $50.7(2.4)$ & $50.6(2.3)$ \\
\hline Ponderal index $\left(\mathrm{kg} / \mathrm{m}^{3}\right)$ & $26.4(2.7)$ & $26.6(3.0)$ & $34.5(1.5)$ \\
\hline Head circumference $(\mathrm{cm})$ & $34.4(1.4)$ & $34.7(1.3)$ & $39.9(1.9)$ \\
\hline Gestational age (weeks) & $40.0(2.0)$ & $39.7(2.4)$ & $28.3(6.1)$ \\
\hline Maternal age (years) & $28.3(6.5)$ & $28.4(6.6)$ & $37.4(4.4)$ \\
\hline Age in $1960^{*}$ (years) & $37.6(4.2)$ & $35.7(4.5)$ &
\end{tabular}

${ }^{*}$ Start of follow up.
Follow up was calculated from 1 November 1960, the census date, to the date of first diagnosis of breast cancer, emigration, death, or end of follow up (31 December 1998), whichever occurred first. We estimated the effect of each birth characteristic on risk of breast cancer as rate ratios using a Cox proportional hazards regression model, where age defined the time scale. To adjust for cohort effects we stratified the models ${ }^{14}$ by five year birth cohorts (1915-9, 1920-4, and 1925-9). As breast cancer may have a different aetiology before and after the menopause we examined associations separately at ages $<50$ years and at older ages, hereafter referred to as premenopausal and postmenopausal ages, respectively. Confidence intervals were computed with robust standard errors to account for correlations among siblings ${ }^{15}$ and Wald tests were used to assess linearity of effects among consecutive exposure categories.

We adjusted for gestational age by including this covariate in Cox models. When we used $\mathrm{z}$ scores of birth characteristics for each gestational age (standardised birth characteristics within each gestational week) our results were similar and thus are not reported here.

\section{Results}

During 1915-29, 6977 girls were born at the Uppsala Academic Hospital, of whom 6552 singletons survived. By 1960, 710 had died and 65 had emigrated. We found personal identity numbers (introduced in the early 1950s) for 5586 (97\%) women. Of these, 5538 were successfully linked to the 1960 census. We nature of the data).

Table 2 Rate ratios* (95\% confidence intervals) and $\mathrm{P}$ value for linear test for trend for incidence of breast cancer at premenopausal ages ( $<50$ years) by selected birth characteristics

\begin{tabular}{|c|c|c|c|c|c|}
\hline Birth size measure & $\begin{array}{l}\text { No of woment } \\
(n=5358)\end{array}$ & $\begin{array}{l}\text { No of cases } \\
(n=63)\end{array}$ & Crude analysis & Adjusted for gestational age & $\begin{array}{l}\text { Adjusted for gestational age } \\
\text { and adult risk factors }\end{array}$ \\
\hline \multicolumn{6}{|l|}{ Birth weight $(\mathrm{g})$ : } \\
\hline$<3000$ & 991 & 7 & 1 & 1 & 1 \\
\hline $3000-3499$ & 2111 & 21 & 1.46 (0.62 to 3.43$)$ & 1.63 (0.70 to 3.79$)$ & 1.61 (0.69 to 3.77$)$ \\
\hline $3500-3999$ & 1674 & 24 & 2.09 (0.90 to 4.85$)$ & 2.48 (1.02 to 6.01$)$ & 2.43 (1.00 to 5.94$)$ \\
\hline$\geqslant 4000$ & 576 & 11 & 2.78 (1.08 to 7.15$)$ & 3.47 (1.30 to 9.27$)$ & 3.48 (1.29 to 9.38$)$ \\
\hline Linear trend & & & $\mathrm{P}=0.01$ & $\mathrm{P}=0.006$ & $\mathrm{P}=0.006$ \\
\hline \multicolumn{6}{|l|}{ Birth length§ (cm): } \\
\hline$\leqslant 49.0$ & 1493 & 9 & 1 & 1 & 1 \\
\hline $49.5,50.0$ & 1136 & 13 & 1.93 (0.83 to 4.50$)$ & 2.13 (0.91 to 4.98$)$ & $2.10(0.89$ to 4.94$)$ \\
\hline $50.5,51.0$ & 1074 & 16 & 2.60 (1.15 to 5.86$)$ & 2.99 (1.32 to 6.75$)$ & 2.94 (1.30 to 6.67) \\
\hline $51.5,52.0$ & 774 & 13 & 3.10 (1.32 to 7.24$)$ & 3.60 (1.54 to 8.40$)$ & 3.53 (1.50 to 8.31$)$ \\
\hline$\geqslant 52.5$ & 861 & 12 & $2.72(1.16$ to 6.41$)$ & 3.37 (1.45 to 7.85$)$ & 3.40 (1.45 to 8.01$)$ \\
\hline Linear trend & & & $\mathrm{P}=0.003$ & $P<0.001$ & $\mathrm{P}<0.001$ \\
\hline \multicolumn{6}{|c|}{ Ponderal index $\left(\mathrm{kg} / \mathrm{m}^{3}\right)$ : } \\
\hline$<24.4$ & 1107 & 10 & 1 & 1 & 1 \\
\hline $24.4-25.7$ & 1049 & 11 & 1.06 (0.44 to 2.56) & 1.07 (0.45 to 2.58) & 1.06 (0.44 to 2.53) \\
\hline $25.8-27.0$ & 1121 & 14 & 1.20 (0.52 to 2.78$)$ & 1.25 (0.54 to 2.89$)$ & 1.25 (0.54 to 2.88$)$ \\
\hline $27.1-28.4$ & 1014 & 13 & $1.21(0.51$ to 2.84$)$ & 1.25 (0.53 to 2.94$)$ & 1.24 (0.52 to 2.93$)$ \\
\hline$\geqslant 28.5$ & 1046 & 15 & 1.34 (0.58 to 3.09$)$ & 1.38 (0.59 to 3.22$)$ & 1.42 (0.61 to 3.32$)$ \\
\hline Linear trend & & & $\mathrm{P}=0.44$ & $\mathrm{P}=0.41$ & $\mathrm{P}=0.37$ \\
\hline \multicolumn{6}{|c|}{ Head circumference $(\mathrm{cm})$ : } \\
\hline$<<3.8$ & 1384 & 7 & 1 & 1 & 1 \\
\hline $33.8-34.0$ & 997 & 10 & $2.03(0.77$ to 5.32$)$ & 2.17 (0.82 to 5.71$)$ & 2.12 (0.81 to 5.58$)$ \\
\hline $34.1-35.0$ & 1559 & 24 & 3.14 (1.36 to 7.24$)$ & 3.50 (1.52 to 8.04$)$ & 3.36 (1.46 to 7.73$)$ \\
\hline $35.1-35.9$ & 344 & 7 & 4.35 (1.54 to 12.29$)$ & 5.05 (1.71 to 14.83$)$ & 5.05 (1.72 to 14.83$)$ \\
\hline$\geqslant 36.0$ & 917 & 14 & 3.39 (1.35 to 8.52$)$ & 3.98 (1.58 to 10.00$)$ & 3.91 (1.54 to 9.93$)$ \\
\hline Linear trend & & & $\mathrm{P}=0.001$ & $\mathrm{P}<0.001$ & $P<0.001$ \\
\hline
\end{tabular}


Table 3 Rate ratios* (95\% confidence intervals) and $\mathrm{P}$ value for linear test for trend for breast cancer incidence at postmenopausal ages ( $\geqslant 50$ years) by selected birth characteristics

\begin{tabular}{|c|c|c|c|c|c|}
\hline Birth size measure & $\begin{array}{l}\text { No of woment } \\
(n=5173)\end{array}$ & $\begin{array}{l}\text { No of cases } \\
(n=296)\end{array}$ & Crude analysis & $\begin{array}{l}\text { Adjusted for } \\
\text { gestational age }\end{array}$ & $\begin{array}{l}\text { Adjusted for gestational } \\
\text { age and adult risk factorsł }\end{array}$ \\
\hline \multicolumn{6}{|l|}{ Birth weight $(g)$ : } \\
\hline$<3000$ & 954 & 60 & 1 & 1 & 1 \\
\hline $3000-3499$ & 2044 & 102 & 0.75 (0.55 to 1.03$)$ & 0.75 (0.54 to 1.03$)$ & 0.75 (0.54 to 1.03$)$ \\
\hline $3500-3999$ & 1617 & 101 & 0.98 (0.71 to 1.35$)$ & 0.98 (0.70 to 1.36$)$ & 0.97 (0.69 to 1.35$)$ \\
\hline$\geqslant 4000$ & 552 & 32 & 0.89 (0.58 to 1.37$)$ & 0.88 (0.56 to 1.37$)$ & $0.87(0.56$ to 1.36$)$ \\
\hline Linear trend & & & $\mathrm{P}=0.83$ & $\mathrm{P}=0.83$ & $\mathrm{P}=0.87$ \\
\hline \multicolumn{6}{|l|}{ Birth length§ (cm): } \\
\hline$\leqslant 49.0$ & 1442 & 77 & 1 & 1 & 1 \\
\hline $49.5,50.0$ & 1096 & 58 & 0.97 (0.69 to 1.36$)$ & 0.97 (0.69 to 1.37$)$ & 0.97 (0.69 to 1.36$)$ \\
\hline $50.5,51.0$ & 1040 & 66 & $1.15(0.83$ to 1.60$)$ & 1.16 (0.84 to 1.62$)$ & $1.13(0.81$ to 1.58$)$ \\
\hline $51.5,52.0$ & 742 & 34 & 0.81 (0.54 to 1.21$)$ & 0.82 (0.54 to 1.23$)$ & $0.80(0.53$ to 1.21$)$ \\
\hline$\geqslant 52.5$ & 833 & 59 & 1.29 (0.92 to 1.82$)$ & $1.30(0.92$ to 1.85$)$ & 1.29 (0.91 to 1.84$)$ \\
\hline Linear trend & & & $\mathrm{P}=0.34$ & $\mathrm{P}=0.34$ & $\mathrm{P}=0.38$ \\
\hline \multicolumn{6}{|c|}{ Ponderal index $\left(\mathrm{kg} / \mathrm{m}^{3}\right)$ : } \\
\hline$<24.4$ & 1076 & 66 & 1 & 1 & 1 \\
\hline $24.4-25.7$ & 1010 & 55 & 0.89 (0.63 to 1.28$)$ & 0.90 (0.63 to 1.28$)$ & $0.88(0.62$ to 1.26$)$ \\
\hline $25.8-27.0$ & 1089 & 65 & 1.01 (0.72 to 1.42$)$ & 1.01 (0.72 to 1.43$)$ & 0.99 (0.71 to 1.40$)$ \\
\hline $27.1-28.4$ & 976 & 58 & $1.02(0.72$ to 1.46$)$ & $1.02(0.72$ to 1.46$)$ & 1.02 (0.71 to 1.45$)$ \\
\hline$\geqslant 28.5$ & 1001 & 50 & 0.85 (0.59 to 1.23$)$ & 0.85 (0.59 to 1.23$)$ & 0.85 (0.59 to 1.23$)$ \\
\hline Linear trend & & & $\mathrm{P}=0.68$ & $\mathrm{P}=0.67$ & $\mathrm{P}=0.67$ \\
\hline \multicolumn{6}{|c|}{ Head circumference (cm): } \\
\hline$<33.8$ & 1335 & 80 & 1 & 1 & 1 \\
\hline $33.8-34.0$ & 967 & 42 & 0.70 (0.48 to 1.02$)$ & 0.70 (0.49 to 1.02$)$ & 0.69 (0.48 to 1.01$)$ \\
\hline $34.1-35.0$ & 1501 & 77 & 0.83 (0.61 to 1.13$)$ & $0.83(0.60$ to 1.14$)$ & $0.82(0.60$ to 1.13$)$ \\
\hline $35.1-35.9$ & 331 & 20 & 0.99 (0.60 to 1.62$)$ & 0.99 (0.60 to 1.62$)$ & 0.97 (0.59 to 1.61) \\
\hline$\geqslant 36.0$ & 883 & 65 & $1.16(0.84$ to 1.61$)$ & 1.16 (0.83 to 1.62$)$ & 1.14 (0.81 to 1.60$)$ \\
\hline Linear trend & & & $\mathrm{P}=0.26$ & $P=0.26$ & $\mathrm{P}=0.29$ \\
\hline
\end{tabular}

*Estimated from Cox survival model, stratified on period of birth (1915-9, 1920-4, 1925-9) and with robust standard errors to account for correlations among siblings.

†Total numbers do not always add up to 5173 because of missing data on specific birth characteristic.

$\neq 0$ ther factors as measured in 1960: marital status, children in the home $(0,1-2,3-4, \geqslant 5)$, age at first marriage $(<25,25-29,30-34$, $\geqslant 35$ years, unmarried), level of education attained (non-academic, A levels, academic), personal car possession (yes/no), occupation (supervisor/non-manual, manual, self employed, unemployed). $\S$ Recorded to the nearest $0.5 \mathrm{~cm}$.

excluded four women with a diagnosis of breast cancer

before the 1960 census. As most of the analyses required gestational age we also excluded 159 women with unknown gestational age and 17 with an unlikely value of less than 30 weeks. Thus we included 5358 women in the reported analyses.

There were 359 cases of breast cancer during the 38 year follow up. Cases were identified through cancer registration, with the exception of three whom we identified through death certificates only. The median age at diagnosis was 62 years (range 36-82), with 63 cases occurring in women aged under 50 years. In addition, 1197 (22\%) women, who had never been diagnosed with breast cancer, died from other causes (median age 68 years, range $31-83$ ) and $37(0.7 \%)$ emigrated during follow up (median age 49, range $31-74$ ).

Table 1 describes the baseline characteristics by breast cancer status and, for cases, by age at diagnosis. Women who developed breast cancer at premenopausal ages had, on average, a larger birth size but a shorter gestational age than those who did not.

There were positive and significant linear trends in rates of breast cancer at premenopausal ages among categories of birth weight, length, and head circumference (table 2). Each of these associations strengthened considerably after we adjusted for gestational age. Rates of breast cancer were 3-4 times higher in women who were in the highest category of any of these measures of birth size compared with those of similar gestational age in the lowest category. Ponderal index showed a positive but non-significant association with risk of premenopausal breast cancer, which did not

alter after we adjusted for gestational age. Women of a higher birth order were at a slightly increased but nonsignificant risk (results not shown), but this effect disappeared after we adjusted for birth weight $(\mathrm{P}=0.98$ for linear trend). Maternal age showed no clear pattern with rates of premenopausal breast cancer (results not shown). There was no evidence of associations between any of the birth size measures available in this study and rates of postmenopausal breast cancer (table 3).

In contrast with the positive associations between measures of birth size and premenopausal risk, for a given birth size a shorter gestation was associated with a significant increase in risk (table 4). No such association was seen for postmenopausal ages.

Simultaneous modelling of the birth size variables and gestational age showed that head circumference was the measure with the strongest independent association with risk of premenopausal breast cancer (table 5). The association with birth weight was greatly reduced and no longer significant after we adjusted for either birth length or head circumference, whereas that for birth length remained of borderline significance after we adjusted for birth weight.

The proxy markers for risk factors for breast cancer had effects in the expected direction. Rates of breast cancer at all ages were higher in women who were single (rate ratio $1.11,95 \%$ confidence interval 0.76 to 1.63 , for single $v$ married women), married later $(1.46,1.06$ to 2.01, for women who married at ages 30-34 v women who married before age 25), or lived in households with fewer children (1.29, 0.93 to 1.80 , for women with no children at home $v$ those with 3 or 4 ). Rates were also 
Table 4 Rate ratios* (95\% confidence interval) and $\mathrm{P}$ values for linear trend for incidence of breast cancer at premenopausal and postmenopausal ages by gestational age

\begin{tabular}{|c|c|c|c|c|c|}
\hline Gestational age (weeks) & $\begin{array}{c}\text { No of } \\
\text { woment }\end{array}$ & No of cases & Crude analysis & $\begin{array}{l}\text { Adjusted for birth size } \\
\text { measures } \neq\end{array}$ & $\begin{array}{c}\text { Adjusted for birth size } \\
\text { measuresł and adult life risk } \\
\text { factors§ }\end{array}$ \\
\hline \multicolumn{6}{|c|}{ Premenopausal ( $<50$ years): } \\
\hline $30-38$ & 1252 & 17 & 1.35 (0.68 to 2.69$)$ & 2.10 (1.05 to 4.21$)$ & 2.06 (1.02 to 4.16$)$ \\
\hline 39 & 1118 & 12 & 1.10 (0.51 to 2.33$)$ & 1.35 (0.65 to 2.80$)$ & 1.30 (0.61 to 2.77$)$ \\
\hline 40 & 1321 & 18 & 1.38 (0.71 to 2.68$)$ & 1.51 (0.78 to 2.92$)$ & 1.45 (0.74 to 2.85$)$ \\
\hline$\geqslant 41$ & 1494 & 15 & 1 & 1 & 1 \\
\hline Linear trend & & & $P=0.34$ & $P=0.03$ & $P=0.03$ \\
\hline \multicolumn{6}{|c|}{ Postmenopausal ( $\geqslant 50$ years): } \\
\hline $30-38$ & 1205 & 68 & $0.93(0.67$ to 1.28$)$ & 0.96 (0.69 to 1.35$)$ & 0.95 (0.68 to 1.34$)$ \\
\hline 39 & 1077 & 62 & 0.93 (0.67 to 1.29$)$ & 0.97 (0.70 to 1.35$)$ & 0.96 (0.69 to 1.34$)$ \\
\hline 40 & 1271 & 67 & 0.87 (0.63 to 1.20$)$ & $0.90(0.65$ to 1.23$)$ & 0.88 (0.64 to 1.22) \\
\hline$\geqslant 41$ & 1448 & 86 & 1 & 1 & 1 \\
\hline Linear trend & & & $\mathrm{P}=0.72$ & $\mathrm{P}=0.64$ & $\mathrm{P}=0.66$ \\
\hline
\end{tabular}

*Estimated from Cox survival model, stratified on period of birth (1915-9, 1920-4, 1925-9) and with robust standard errors to account for correlations among siblings. †Analyses restricted to women with complete data for gestational age, birth weight, birth length, and head circumference.

fLength, weight, and head circumference.

$\S 0$ ther factors as measured in 1960: marital status, children in the home $(0,1-2,3-4, \geqslant 5)$, age at first marriage $(<25,25-29$, 30-34, $\geqslant 35$ years, unmarried), level of education attained (non-academic, A levels, academic), personal car possession (yes/no), occupation (supervisor/non-manual, manual, self employed, unemployed)

higher in women who were supervisors or non-manual workers, had their own car, and had had an academic education. There was, however, no evidence that the associations between the birth characteristics and risk of breast cancer were confounded by these adult characteristics (see tables 2 and 4 ) nor by maternal socioeconomic status at birth (results not shown).

\section{Discussion}

\section{Main findings}

We have found strong evidence of positive associations between measures of birth size and risk of premenopausal breast cancer, which persisted after we adjusted for markers of adult risk factors and were strengthened after we adjusted for gestational age. In addition, for a given birth size a shorter gestation was associated with a significantly increased risk of premenopausal breast cancer. The positive association with birth size and independent inverse association with gestational age indicate that the rate of fetal growth may underlie the association between birth size and risk of early breast cancer. There was no evidence of an association with postmenopausal risk.

The Uppsala birth cohort study comprises a large population based cohort with long and almost complete follow up and enough events to enable separate analysis at premenopausal and postmenopausal ages. Data on a large number of birth measurements allowed us to examine their independent effects and their effects adjusted for gestational age so we could obtain a measure of the fetal growth rate. As birth characteristics were measured and recorded at the

Table 5 Mutually adjusted rate ratios* (95\% confidence interval) and $\mathrm{P}$ value for linear test for trend for incidence of breast cancer at premenopausal ages ( $<50$ years) by selected measures of birth size

\begin{tabular}{|c|c|c|c|c|c|}
\hline \multirow{2}{*}{$\begin{array}{l}\text { Birth size } \\
\text { measure }\end{array}$} & \multirow{2}{*}{$\begin{array}{c}\text { Adjusted for gestational } \\
\text { aget only }\end{array}$} & \multicolumn{4}{|c|}{ Adjusted for gestational age $\nmid$ and } \\
\hline & & Birth weight & Birth length & Head circumference & Other two measures \\
\hline \multicolumn{6}{|l|}{ Birth weight $(\mathrm{g})$ : } \\
\hline$<3000$ & 1 & - & 1 & 1 & 1 \\
\hline $3000-3499$ & $1.63(0.70$ to 3.79$)$ & - & 1.00 (0.41 to 2.44$)$ & 0.99 (0.44 to 2.24$)$ & 0.70 (0.30 to 1.63$)$ \\
\hline 3500-3999 & 2.48 (1.02 to 6.01$)$ & - & $1.20(0.44$ to 3.30$)$ & $1.18(0.51$ to 2.72$)$ & 0.70 (0.27 to 1.78$)$ \\
\hline$\geqslant 4000$ & 3.47 (1.30 to 9.27$)$ & - & $1.58(0.45$ to 5.52$)$ & $1.32(0.48$ to 3.60$)$ & $0.73(0.22$ to 2.44$)$ \\
\hline Linear trend & $P=0.006$ & & $\mathrm{P}=0.37$ & $\mathrm{P}=0.47$ & $\mathrm{P}=0.79$ \\
\hline \multicolumn{6}{|c|}{ Birth length $\neq(\mathrm{cm})$ : } \\
\hline$\leqslant 49.0$ & 1 & 1 & - & 1 & 1 \\
\hline 49.5 to 50.0 & 2.13 (0.91 to 4.98$)$ & 2.03 (0.88 to 4.69$)$ & - & $1.61(0.71$ to 3.64$)$ & $1.80(0.80$ to 4.07$)$ \\
\hline 50.5 to 51.0 & 2.99 (1.32 to 6.75$)$ & 2.69 (1.16 to 6.22$)$ & - & $1.90(0.89$ to 4.06$)$ & $2.18(0.96$ to 4.94$)$ \\
\hline 51.5 to 52.0 & 3.60 (1.54 to 8.40$)$ & 3.00 (1.15 to 7.86$)$ & - & 2.31 (0.99 to 5.42$)$ & 2.64 (1.02 to 6.81$)$ \\
\hline$\geqslant 52.5$ & 3.37 (1.45 to 7.85$)$ & $2.59(0.90$ to 7.47$)$ & - & 2.03 (0.88 to 4.68$)$ & 2.30 (0.83 to 6.39$)$ \\
\hline Linear trend & $\mathrm{P}<0.001$ & $P=0.09$ & & $\mathrm{P}=0.06$ & $\mathrm{P}=0.12$ \\
\hline \multicolumn{6}{|c|}{ Head circumference $(\mathrm{cm})$ : } \\
\hline$<33.8$ & 1 & 1 & 1 & 一 & 1 \\
\hline $33.8-34.0$ & 2.17 (0.82 to 5.71$)$ & 2.11 (0.80 to 5.52$)$ & 1.87 (0.72 to 4.87$)$ & - & 2.03 (0.78 to 5.27$)$ \\
\hline $34.1-35.0$ & 3.50 (1.52 to 8.04$)$ & 3.27 (1.48 to 7.20$)$ & 2.68 (1.19 to 6.04$)$ & - & 2.95 (1.35 to 6.46$)$ \\
\hline $35.1-35.9$ & 5.05 (1.71 to 14.83$)$ & 4.49 (1.63 to 12.37$)$ & 3.67 (1.29 to 10.44$)$ & - & 3.99 (1.46 to 10.87$)$ \\
\hline$\geqslant 36.0$ & $3.98(1.58$ to 10.00$)$ & 3.40 (1.31 to 8.83$)$ & $2.73(1.07$ to 7.00$)$ & - & 2.97 (1.15 to 7.66$)$ \\
\hline Linear trend & $\mathrm{P}<0.001$ & $\mathrm{P}=0.006$ & $\mathrm{P}=0.02$ & & $\mathrm{P}=0.02$ \\
\hline
\end{tabular}


timeof birth they were not affected by recall bias. Other than measures of birth size, however, we did not have any other information about intrauterine factors. We adjusted for risk factors in adult life using proxy markers obtained from census data, although there is still potential for residual confounding. Ascertainment of cases of breast cancer during follow up was virtually complete, ${ }^{16}$ but a few cases in young women might have been missed if they were diagnosed before the start of follow up in 1960.

\section{Comparison with other studies}

Our findings are consistent with those from a British cohort $^{11}$ and a case-control study nested within the nurses' health study, ${ }^{10}$ in which positive associations were found with birth weight, particularly at young ages. We did not find evidence for a $\mathrm{J}$ shaped association as has been reported elsewhere. ${ }^{3467}$ Our observed positive association with birth length agrees with findings from two other studies. ${ }^{39}$ Also Ekbom et al found a significantly increased risk in women who had been born very prematurely, ${ }^{517}$ though no such association was found in the nurses' health study. ${ }^{10}$ However, in the nurses' health study maturity at birth was recalled by the participants' mothers and was thus prone to greater error than in our study. Lastly, our adjustment for gestational age or stratification by menopausal status, or both, may have led to differences in magnitude of effects with respect to other studies. ${ }^{9-11}$

We found that the associations of birth length and head circumference with premenopausal risk were stronger than those for birth weight and that there was no association with ponderal index, suggesting that linear (bone) growth may be a more sensitive indicator of the relevant biological processes. Length at birth is a stronger predictor of adult height than birth weight. ${ }^{18} 19$ Thus, the association of adult height with risk of breast cancer ${ }^{20}$ may in part reflect prenatal as well as postnatal influences.

\section{Biological plausibility and implications}

Trichopoulos hypothesised that prenatal exposure to high concentrations of pregnancy oestrogens influences risk of breast cancer. ${ }^{1}$ The mammary gland starts to develop in utero, when it is in a partially undifferentiated state, and high concentrations of growth factors may result in an increased number of stem cells or increased mitosis, or both. But although there is strong evidence that a woman's endogenous oestrogen concentrations are important in the aetiology of postmenopausal breast cancer, ${ }^{21}$ their role at premenopausal ages is less clear. ${ }^{22}$ Our findings are consistent with those from recent prospective studies that have shown a strong association between high circulating concentrations of insulin-like growth factor I in adulthood and subsequent risk of premenopausal, but not postmenopausal, breast cancer. ${ }^{23} 24$

In public health terms, if the findings were real, large birth size would be responsible for only a small proportion of the total number of cases of breast cancer in any population as the incidence at premenopausal ages is low. The association of larger size at birth with an increased risk of premenopausal breast cancer should be considered in light of its opposite association with ischaemic heart disease, ${ }^{13} \mathrm{a}$ much more common condition.

\section{What is already known on this topic}

There is some evidence that birth weight is related to risk of breast cancer

The exact nature of any association and whether it differs at premenopausal and postmenopausal ages is unclear

Few studies have examined the effect of other measures of birth size and of gestational age

What this study adds

There are strong positive associations between measures of birth size and rates of breast cancer at premenopausal ages that persisted after adjustment for adult risk factors

For a given birth size, gestational age was inversely associated with risk, suggesting that the rate of fetal growth may be aetiologically relevant to premenopausal breast cancer

There was no association between birth characteristics and rates of breast cancer at postmenopausal ages

In summary, our results provide strong evidence that there is real association between birth size and risk of breast cancer at premenopausal ages and that fetal growth rate, rather than size at birth alone, may be the aetiological relevant factor.

Contributors: HOL and DAL were responsible for the setting up and scientific management of the Uppsala birth cohort study. RM maintained the study database. DAL proposed this study. VAMcC conducted the statistical analysis and wrote the first draft of the paper under supervision of BLDS and IdSS, and is guarantor. All authors contributed to the interpretation of the findings and to the final version of the paper.

Funding: The Uppsala birth cohort study was established on grants provided by the UK Medical Research Council (No 9322050), the Swedish Council for Social Research (No 94/0157), and the Swedish Medical Research Council (No 5446). This work was conducted within the MRC Cooperative on "Life-course and trans-generational influences on disease risk" (G9819083).

Competing interests: None declared.

1 Trichopoulos D. Hypothesis: does breast cancer originate in utero? Lance 1990;335:939-40.

2 Le Marchand L, Kolonel LN, Myers BC, Mi MP. Birth characteristics of premenopausal women with breast cancer. Br J Cancer 1988;57:437-9.

3 Ekbom A, Trichopoulos D, Adami HO, Hsieh CC, Lan SJ. Evidence of prenatal influences on breast cancer risk. Lancet 1992;340:1015-8.

4 Sanderson M, Williams MA, Malone KE, Stanford JL, Emanuel I, White E, Sanderson M, Williams MA, Malone KE, Stanford JL, Emanuel, White E,
et al. Perinatal factors and the risk of breast cancer. Epidemiology 1996;7:34-7.

5 Ekbom A, Hsieh CC, Lipworth L, Adami HQ, Trichopoulos D. Intrauterine environment and breast cancer risk in women: population-based study. J Natl Cancer Inst 1997;89:71-6.

6 Innes K, Byers T, Schymura M. Birth characteristics and subsequent risk for breast cancer in very young women. Am J Epidemiol 2000;152:1121-8.

7 Titus-Ernstoff L, Egan KM, Newcomb PA, Ding J, Trentham-Dieta A, Greenberg ER, et al. Early life factors in relation to breast cancer risk in postmenopausal women. Cancer Epidemiol Biomark Prev 2002;11:207-10.

8 Sanderson M, Shu XO, Jin F, Dai Q, Ruan Z, Gao Y-T, et al. Weight at birth and adolescence and premenopausal breast cancer risk in a low-risk population. Br J Cancer 2002;86:84-8.

9 Vatten LJ, Maehle BO, Lund Nielsen TI, Tretli S, Hsieh C-C, Trichopoulos D, et al. Birthweight as a predictor of breast cancer: a case-control study in Norway. BrJ Cancer 2002;86:89-91.

10 Michels KB, Trichopoulos D, Robins JM, Rosner BA, Manson JE, Hunte $\mathrm{DJ}$, et al. Birthweight as a risk factor for breast cancer. Lance 1996;348:1542-6.

11 De Stavola BL, Hardy R, Kuh D, dos Santos Silva I, Wadsworth M, Swerdlow AJ. Birthweight, childhood growth and risk of breast cancer in a British cohort. Br J Cancer 2000;83:964-8. 
12 Leon DA. Fetal growth and later disease: epidemiological evidence from Swedish cohorts. In: Shaughn O'Brien PM, Wheller T, Barker DJ, eds. Fetal programming: influences on development and disease in later life. London: Royal College of Obstetricians and Gynaecologists Press, 1999.

13 Leon DA, Lithell HO, Vägerö D, Koupilová I, Mohsen R, Berglund L, et al. Reduced fetal growth rate and increased risk of death from ischaemic
heart disease: cohort study of 15000 Swedish men and women born 1915-29. BMJ 1998:317:241-5.

14 Marubini E, Valsecchi MG. Analysing survival data from clinical trials and observational studies. New York: Wiley 1994.

15 Diggle P. Analysis of longitudinal data. Oxford: Oxford University Press 1994.

16 Garne JP, Aspegren K, Moller T. Validity of breast cancer registration from one hospital into the Swedish National Cancer Registry 1971-1991. Acta Oncol 1995;34:153-6.

17 Ekbom A, Erlandsson G, Hsieh C, Trichopoulos D, Adami HO, Cnattingius S. Risk of breast cancer in prematurely born women. J Natl Cancer Inst 2000;92:840-1.

18 Sørensen HT, Sabroe S, Rothman KJ, Gillman M, Steffensen FH, Fischer $\mathrm{P}$, et al. Birth weight and length as predictors for adult height. Am J Epidemiol 1999;149:726-9.
19 Tuvemo T, Cnattingius S, Jonsson B. Prediction of male adult stature using anthropometric data at birth: a nationwide population-based study. Pediatric Res 1999;46:491-5.

20 Van den Brandt PA, Spiegelman D, Yaun SS, Adami HO, Beeson L, Folsom AR, et al. Pooled analysis of prospective cohort studies on height, weight, and breast cancer risk. Am J Epidemiol 2000;152:514-27.

21 Endogenous Hormones and Breast Cancer Collaborative Group. Endogenous sex hormones and breast cancer in postmenopausal women: reanalysis of nine prospective studies. J Natl Cancer Inst 2002;94:606-16.

22 Thomas HV, Key TJ, Allen DS, Moore JW, Dowsett M, Fentiman IS, et al. A prospective study of endogenous serum hormone concentrations and breast cancer risk in premenopausal women on the island of Guernsey. Br J Cancer 1997;75:1075-9.

23 Hankinson SE, Willett WC, Colditz GA, Hunter DJ, Michaud DS, Deroo $\mathrm{B}$, et al. Circulating concentrations of insulin-like growth factor-I and risk of breast cancer. Lancet 1998;351:1393-6.

24 Toniolo P, Bruning PF, Akhmedkhanov A, Bonfrer JM, Koenig KI Lukanova A, et al. Serum insulin-like growth factor-I and breast cancer. Int J Cancer 2000;88:828-32.

(Accepted 4 November 2002) 